\title{
Mujeres, barrio e investigación: ejercicio de autoreflexión desde una trayectoria investigadora y activista en Geografía (2002-2011)*
}

\author{
Women, and Research District: An Exercise of Self-reflection on a \\ Career of Research and Activism in Geography (2002-2011)
}

\author{
Fabià Díaz-Cortés \\ School of Geography, University of Leeds \\ fabiadiazcortes@gmail.com
}

\section{Resumo}

El presente artículo tiene el interés de centrarse en un repaso de mi trayectoria investigadora de los últimos nueve años, centrada en el estudio de barrios de tradición obrera y popular en la región metropolitana de Barcelona, teniendo en cuenta: 1) las experiencias vivenciales de mujeres residentes en tres barrios donde he desarrollado trabajo de campo y, 2) la participación en espacios de participación directa de mujeres en mi entorno cotidiano. La experiencia acumulada reclama de revisiones periódicas, donde se analice el papel de la investigadora, del proceso investigador y de la contribución al lugar y a los objetivos propuestos, y en este contexto hay que situar el presento ejercicio autoreflexivo en geografía.

Palabras-clave: geografía y género; mujeres; barrio; academia y activismo en el entorno cotidiano; autoreflexividad.

\begin{abstract}
This article is aimed to focus on a reflection on my research history in the last nine years, based on the study of working-class neighborhoods and popular tradition in the metropolitan area of Barcelona, taking into account: 1) the life experiences of women living in three neighborhoods where I performed a field work, 2) the influence of wom-en in areas of direct participation of women in my daily life. The experience relies on periodic reviews, which examine the role of the researcher, the research process, and its contribution to the place and the proposed objectives. It is in this context that this exer-cise in self-reflection lies on Geography.
\end{abstract}

Keywords: geography and gender; women; neighborhood; academia and activism in everyday life; self-reflexion. 
En el año 2002 empecé a desarrollar un trabajo de investigación que tenía por objeto de estudio la vida cotidiana en espacios públicos, teniendo como variable más importante los aspectos relacionados con el género y el uso y apropiación que hacían mujeres y hombres de determinadas plazas de barrio (DÍAZCORTÉS, 2004). Esta oportunidad se originó desde el del Grup de Recerca de Geografia i Gènere de la Universitat Autònoma de Barcelona (http:/geografia.uab.es/genere/), dirigido por la geógrafa María Dolors Garcia Ramon, que encabeza y coordina un equipo de trabajo referencial en Catalunya $\mathrm{y}$ en Estado español en el ámbito de las investigaciones en geografía y género y con una destacable proyección académica a través de redes internacionales en el ámbito de la geografía y género y geografía feminista.

Este primer trabajo pude desarrollarlo en el contexto de un barrio de clase traba-jadora, $\mathrm{Ca}$ n'Anglada de Terrassa, que tenía sus orígenes en las migraciones interiores que tuvieron lugar en el Estado español una vez iniciada la dictadura franquista en los años cuarenta del siglo pasado, una realidad que conocía bien, ya que son mis orígenes y me he criado en esos ambientes sociales y urbanos. Se trataba de una área urbana donde el aspecto autoconstructivo, urbanizando el propio vecindario el barrio, empezando por sus propias casas, y dignificándolo a través de la lucha vecinal, en un contexto de penurias y sacrificios generalizados, suponía la existencia de un fuerte sentido de identidad y arraigo al lugar (BATALLA, 1986; BALLARÍN, CASAS ; MÁRQUEZ, 1996), una realidad que responde a un modelo más general y estructural de la geografia urbana catalana y española (CANDEL, 1964; CASTELLS, 1977; VÁZQUEZ MON-TALBÁN y MORENO, 1991; LLIGADES ; DE MAYA, 2000; MARÍN, 2004; ARANGO, 2007; PUJADAS, 2007). Al mismo tiempo, destacaba el hecho que era un barrio donde se habían concentrado, en relativamente muy poco tiempo, dos grandes procesos migratorios en diferentes períodos de la historia del barrio: el primero, a mediados del siglo pasado (destacando los asentamientos de personas provenientes del sur del Estado español); y, el segundo, a caballo entre final del siglo pasado e inicio del actual (destacando los asentamientos de personas provenientes del Estado marroquí).

Un segundo trabajo lo inicié en 2005. Lo concebí como un ejercicio comparativo con el anterior caso, teniendo en cuenta procesos socioterritoriales que eran idénticos y, también, de particulares, y con el interés de relacionarlo con el papel de la administración municipal en estos procesos. Escogí un barrio de la misma ciudad, Can Palet de Terrassa, que compartía parte de la historia y del presente del barrio de $\mathrm{Ca}$ n'Anglada, pero tenía algunas particularidades, sobre todo en lo que se refiere a procesos migratorios. Este segundo barrio tenía sus orígenes a principios de siglo pasado, por lo que tenía una ligera mayor variedad en lo que se refiere a asentamientos de diferentes culturas a lo largo de la historia del barrio (destacando el caso de la catalana, andaluza y marroquí, entre otras, y las tres en diferentes períodos históricos) (DÍAZCORTÉS, 2009).

Un tercer trabajo lo inicié en el año 2010, una vez finalizada la tesis doctoral, y seguía con el hilo conductor de los barrios obreros pero circunscribiendo la investigación en un ámbito próximo y cotidiano para mí, un barrio de la ciudad donde he vivido toda mi vida, La Romànica de Barberà del Vallès ${ }^{1}$.

Como se ve, si bien al principio el ámbito de estudio eran plazas de barrio, el trabajo de campo, la propia gente con su vida cotidiana y el interés personal me llevó a hacer del barrio el ámbito de estudio de referencia, teniendo en cuenta aspectos como el proceso de construcción urbanística del barrio, el proceso de configuración de identida-des, las relaciones comunitarias y la participación asociativa y política $\mathrm{y}$, finalmente, las políticas de barrio desarrolladas desde las administraciones públicas, sin olvidar el papel que el sector privado también juega en los barrios, e interrelacionando estos procesos con dimensiones como el género, la edad, el origen étnicocultural y la clase social (HAYDEN, 1995; RUDDICK, 1996; LEE, 2007).

En un primer momento, que corresponde a los dos primeros trabajos, las investi-gaciones se basaban en un trabajo de campo cualitativo, donde la recogida de fuentes orales, a través de entrevistas en profundidad, y la observación no participante eran las técnicas básicas del trabajo de campo, además de la participación en espacios asociativos o en la misma vida social de las dos áreas de estudio, poniendo en práctica la necesidad de generar un conocimiento que no esté desligado de la experiencia cotidiana de las personas y situado (TAYLOR y BOGDAN, 1996; DRIVER, 2003; RILEY ; HARVEY, 2007; GEORGE ;STRATFORD, 2010; HAY, 2010; KEARNS, 2010) como se reclama y práctica desde de la geografía feminista (MCDOWELL, 1992; KATZ, 1994; CRANG，2002 ，2005; DAVIES ; DWYER, 2007; GARCIA-RAMON, 2008). Se trataba de aplicar técnicas preconcebidas, que para mi eran y siguen siendo útiles, en lugares que, aunque próximos, no eran cotidianos para mí. Eso me supuso incomodidades y re-consideraciones, como se expresa en otros trabajos desarrollados por geógrafas (BENSON ; NAGAR, 2006; LOBO, 2010; PALMARY, 
2011) ya que no podía asegurar mi implicación personal -el ser útil social y políticamente- ni podía contribuir como yo quería a consolidar dinámicas socio-espaciales en los lugares donde desarrollaba mi tra-bajo de campo.

Esa cierta frustración fue expresada en mis conclusiones de la Tesis Doctoral, donde me proponía iniciar un nuevo camino donde la geografía volvería y se vincularía a mi vida cotidiana, a mi entorno más próximo y vivencial, un ámbito social donde ya colaboraba asociativa y políticamente con otras compañeras y compañeros, y que no dejar de ser otra forma de hacer geografía vinculada un posicionamiento situado e im-plicación situada, en lo personal, cotidiano y político (CAHILL, 2007; CHARTTER-TON ; PICKERILL, 2010). Era aquí donde estaba siendo posible ser y sentirme útil, donde los proyectos de investigación podían tener un claro arraigo y desarrollo coheren-te en el tiempo, y no eran simples apariciones y desapariciones, como suele ocurrir a menudo en muchos de estos barrios cuando se aplican programas de actuación social y comunitaria que yo mismo había criticado de forma argumentada (DÍAZ-CORTÉS, 2009).

Desde este punto de partida, de la necesidad de analizar críticamente lo desarrol-lado en mi trayectoria hasta ahora como geógrafo, es desde donde nace el interés por revisitar la experiencia con las mujeres con las que he entrado en contacto en mis investigaciones, como se pone de manifiesto en otros trabajos (LEE, 2007), pero también en mis espacios de implicación asociativa y política, con el objetivo de hacer un ejercicio de reflexividad sin renunciar a mi posicionalidad y experiencia vivida (ENGLAND, 1994; EKINSMYTH, 2002).

\section{Revisitando la experiencia vivencial en el barrio de las mujeres a través de la fuente oral}

Lo que se expone a continuación son las líneas generales en las opiniones que se han recogido a sesenta y nueve mujeres en cincuenta y ocho entrevistas en tres áreas de estudio diferentes, pero que comparten el hecho de ser barrios humildes situados en la región metropolitana de Barcelona. Sí que quiero advertir que este apartado no tiene el interés de ofrecer una fotografía de qué opinan las mujeres de los barrios, sino y estric-tamente, las mujeres que he entrevistado, teniendo en cuenta que otras experiencias y vivencias en los barrios enriquecerían aún más lo expuesto aquí. En todo caso, lo que se pone de manifiesto en las siguientes líneas es que el sujeto mujer no responde a un único marco general y homologable para todo el colectivo de mujeres -lo mismo podríamos decir de los barrios- aún compartiendo tanto lugares de residencia que pueden resultar altamente homogéneos como procesos estructurales de socialización, dominación y discriminación, un aspecto que situa el siguiente análisis en el ámbito teórico y meto-dológico de la interseccionalidad (VALENTINE, 2008).

\section{Sobre el Hogar, el Trabajo Asalariado y la Participación Asociativa}

Un primer aspecto que habría que destacar, a partir de las opiniones de las muje-res entrevistadas en los tres barrios, es que mayoritariamente expresan una vinculación cotidiana e intensa con el trabajo doméstico, destacando algunas opiniones que normalizan $\mathrm{y}$ asumen las tareas del hogar como una responsabilidad de ellas y que son expuestas tanto por mujeres mayores como jóvenes:

Me levanto a los ocho o así o ocho y media,
hago las cosas de la casa, si tengo que ir a
comprar voy aquí cerca, [...] vengo, hago la
comida, mi marido viene a las dos.
Comemos. Y si es ahora, me traen al niño a
las cuatro y ya no puedo salir hasta que se
lo llevan. Ahí toda la tarde vigilando al
niño o haciendo un poquito de croche, o
viendo la tele, y ya está. [...] Antes me iba
al gimnasio a las tres y media, me iba al
gimnasio ahí al Parc Vallès y venía a las
cinco y media o a las seis y ya te ponías a
hacer la comida por la noche. [...] Esa es la
vida. Sacando los sábados que vas a dar
una vuelta, a tomarte una cerveza, a dar
una vuelta, o a Sabadell al Corte Inglés.
Esa es mi vida, un día y otro, igual, igual,
igual2. Ángela, barrio de Can Palet, 64
años, casada, no tiene trabajo remunerado.
Originaria de Montejaque (Andalucía,
España).

Si bien es una tónica general en casi todas las entrevistas, también cabe reseñar que buena parte de ellas combinan el trabajo doméstico no remunerado con el trabajo fuera de casa remunerado, pero poniéndose al mismo tiempo de manifiesto que en diversos casos, y de nuevo para mujeres mayores y jóvenes, han dejado empleo a partir de la presión de sus maridos o compañeros o por considerarlo necesario para poder asumir las tareas domésticas, sobre todo de cuidado y atención a sus hijos e hijas: 
Bueno, esto es muy complicado... siempre ha sido complicado pero ahora más. El tema doméstico lo llevo más yo que él porqué es así. Tenemos una chica en casa que nos ehca una mano, los lunes que yo tengo fiesta en la peluquería. Y antes lo que hacía los lunes era que estudiava de mi sector. Siempre estaba haciendo cursos de mil cosas.[...] Desde que tengo al Ar-nau,yo esta parte la he renunciado y desde hace, pués, 20 meses no hago nada de mi faena. Hago de 'mami' los lunes. Lo hago más yo que él. Yo he dejado mi parte y mi marido no, él sigue estudiando. Y las faenas de casa, yo creo que el $70 \%$ las llevo yo. [...] El Arnay sí que lo compartimos pero lo que es ordenar, pasar la aspiradora, la ropa, la comida.... me toca más a mí que a él.[...] Yo me casé muy joven, tenía 22 años cuando me casé y tendríamos que haber dichot: yo pongo la lavadora el lunes y tú martes pero bueno, yo empezé a vivir con y como que ya lo tenía un poco aceptado por la educación que recibí en mí casa y seguimos igual. [...] No está compartida la faena en casa y yo tampoco he sido una cosa me haya puesto nunca mal con él por esto, yo creo que parte de culpa la tiene esto, eh!, en casa, mi padre es de los que pide las zapatillas y bueno, pués yo, no tanto, porqué eso ya sería la hostia, pero lo tengo un poco asumido desgraciadamente. Sandra, barrio de La Romànica, 35 años. Casada con un hijo, tiene trabajo remunerado. Nacida en Sabadell (Catalunya).

De forma más residual se ha hecho mención al hecho de estar estudiando, estar en el paro y buscando trabajo o, aún queriendo trabajar, no poder hacerlo al estar de baja por enfermedad.

\section{Sobre la Vivencia del Espacio Público}

En primer lugar, tendríamos que remarcar el hecho de que la movilidad de las mujeres entrevistadas se hace a pie, sobre todo en el ámbito del barrio, y muy pocas de ellas expresan el hecho de compartir el uso del coche con el caminar o usarlo exclusi-vamente. La vivencia cotidiana en el barrio nos pone de manifiesto otra importante di-námica socio-espacial que querríamos destacar, en relación a como las mujeres viven y concibe el espacio público como diverso, incluyendo espacios abiertos y cerrados, pú-blicos y privados. En este sentido, resalta comprobar como la mayoría de ellas señalan espacios cerrados como los lugares preferentes de reunión y encuentro con otras perso-nas, y en menor medida, espacios abiertos, como podría ser el caso de las plazas, acom-pañando a hijas e hijos:

Quedamos así, en una panadería para tomar algo. Con mis paisanas a veces vienen a mi casa, te ves en casa. Antes utilitzaba el centro cívico para hacer internet. A la biblioteca antes iba mucho, a la Biblioteca Central, ahora a la de Ca n'Anglada, pero como no estudio para ir a buscar información, y a veces voy para ver si tengo algún mensaje, y ya está. Saida, barrio de Ca n'Anglada, 19 años. Vive en el hogar familiar, estudia. Originaria de Nador (Marruecos).

En relación a este último aspecto destacar que cuando se hace mención al hecho de usar o no plazas del mismo barrio se pone de manifiesto el hecho de sentirse incó-modas en lugares donde exista presencia masculina, situación que las hace optar por otros tipos de espacios más íntimos o lugares fuera de los barrios de residencia. Cuando se comenta esta situación la relación entre masculinización y etnicización es importante, tanto para mujeres que podríamos considerar autóctonas como de origen extranjero:

Alli para sentarse no... no te puedes sentar. Porqué allí... porqué mis paisanos allí se quedan allí todos, porqué hacen parques para los niños y se sientan en ellos. La calle siempre está llena. Yo... aunque sean mis paisanos, pero yo no lo entiendo. Es que no... no sé si es la falta de educación o algo, pero no es... no sé. No lo entiendo ni yo, te vienen, te quedas en una esquina, se llenan todas las plazas... yo no lo entiendo, me cuesta entenderlo. Saida, barrio de Ca n'Anglada, 19 años. Vive en el hogar familiar, estudia. Originaria de Nador (Marruecos).

Femeninos no hay nadas, lo encuentro muy machista. Por ejemplo, entrar en un bar a tomar un café con leche, que es lo que hago, bueno un café con leche, quiero decir, yo es lo que tomo, y yo me encuentro con las miradas machistas que hay aún, mucho. Cesca, barrio de Can Palet, 54 años, separada con un hijo y dos hijas mayores 
de edad, de baja médica. Originaria de Almería (Andalucía, España).

Otra aspecto a destacar es que se exprese el hecho que desde pequeñas se les imponen normas y actividades por el hecho de ser mujeres, o que existen pautas de con-trol y discriminación desde el ámbito familiar entre hermanas y hermanos, siendo opini-ones que se expresan tanto por parte de mujeres de origen extranjero como autóctono:

Mi madre... o sea, mi madre es muy... o sea, mi abuela era muy así, es del palo, si es una chavala y está aquí tiene que limpiar tiene que no sé qué... o sea, a lo mejor son ideas un poco... no es que sea machista ni nada, pero que ya estás acostumbrado. A lo mejor mi padre se sienta en el sofá y yo tengo que hacer las cosas. No es que no sean machista ni nada. Marta, barrio de Can Palet, 17 años. Vive en el hogar familiar, estudiante de bachillerato. Nacida en Terrassa (Catalunya).

\section{Sobre las Relaciones Comunitárias}

Si una opinión destaca sobre el resto es el hecho de problematizar la inmigración en el barrio, añadiéndose opiniones que muestran una visión negativa en general, lle-gando al extremo de vincular este posicionamiento con el hecho de sentir miedo cuando van por las calles o que las personas recién llegadas suponen una degradación para el barrio, como hemos comentado. Otras opiniones apuntan al hecho de la 'masificación' de persones de origen extranjero como negativo:

Pero hay mucha gente inmigrante que por lo que sea, no sé, están haciendo mucha más vida en la calle que hacemos nosotros, no sé si es porqué sus viviendas no están en condiciones, no lo sé, pero hacen la vida en la calle [...]. Se reúnen en la calle, pero no son los... no son todos los hombres, son los hombres inmigrantes de una determinada.... [...] esta gente se reúne en la calle, y además, tú... yo personalmente me siento violentada cuando tengo que pasar por delante de ellos, porqué no te dejan pasar, tienes que ser tú que tienes que dar toda la vuelta. Martina, barrio de Can Palet, 34 años. Casada con hijos, tiene trabajo remunerado. Nacida en Terrassa (Catalunya).
En cambio, y como contrapunto a lo anterior, también son destacables las respu-estas que, cuando se pregunta si se tienen contacto o no con personas de origen extranje-ro, responden que no, y sin poner de manifiesto una posición de rechazo o una postura premeditada sino, simplemente, que no se tienen relaciones, siendo muy pocas las muje-res que dejan claro que sí que evitan relacionarse:

Pasó una vez pero sólo era que te decían alguna cosa y ya está y después pasabas, pero tampoco le das más importancia, si me lo dicen pués me lo dicen y ya está, y paso. Chloe, barrio de Ca n'Anglada, 19 años. Vive en el hogar familiar, estudia. Nacida en Terrassa (Catalunya).

En todo caso, las mujeres de origen extranjero entrevistadas sí que exponen, en su mayoría, el hecho de sentir o haber sentido discriminación directa en el barrio:

Por mi experiencia aquí, de veces, cuando salgo, me veo rechazada por la gente. La mayoría te rechaza, a lo mejor por la lengua que hablo con mi hijo o así, marroquí, o algo así. Pero lo primero que sientes es que la gente te rechaza. Y a lo mejor después y tal, cuando empieza a jugar el niño y tal, te encuentras unas personas que son más amables y te entienden mejor, pero la primera sensación es rechazo de la gente, no sé por qué. A lo mejor porqué ven que soy extranjera, a lo mejor por el velo, por el velo que yo llevo fuera, a lo mejor sí, pero no lo entiendo esto. Pero tampoco no lo puedo generalizarlo, porqué hay gente que te entiende. Suleima, barrio de Can Palet, casada con un hijo, tiene trabajo remunerado. Originaria de Ksar-el-Kbir (Marruecos).

De forma menos general, pero destacable, se expondrían las opiniones de nor-malización del hecho migratorio sin expresar prejuicios ni aspectos de problematización, coincidiendo con el caso de mujeres que sí que explican que tienen relaciones cotidianas con mujeres de otros orígenes culturales:

Yo pienso que bueno, igual que mi marido vino trasladado, no vinimos así directamente, pero es lo mismo, si el hubiera tenido un buen trabajo no nos 


\begin{abstract}
hubiéramos venido. Igual que nosotros venimos aquí buscando una vida mejor, pues es porque se necesitaba y tendríamos que estar de acuerdo que ahora también viene gente de fuera buscando una vida mejor porque lo necesitan. Hay mucha gente que no lo acepta y yo eso lo veo muy mal. Otra cosa, igual, comportamiento, hay en todos los sitios. En todos los países hay personas que se comportan bien y otras que no, en el nuestro también. Así que no porque unos se porten mal, hay que meterlos a todos en el mismo saco. Juana, barrio de La Romànica, 72 años, casada con hijos mayores. Originaria de Argamasilla de Calatrava (Ciudad Real, España).
\end{abstract}

En todo caso, también queremos señalar un aspecto que suele pasar desapercibi-do ante la monopolización mediática centrada en los conflictos interétnicos, y que tam-bién se ha puesto de manifiesto en ámbitos asociativos, y es el de las problemáticas y conflictos intergeneracionales, expresándose poca sintonía y relación entre entidades y espacios más de ámbito juvenil y las que tienen presencia mayoritaria de personas ma-yores:

\begin{abstract}
¿Que qué relación hay entre l'Espai 'La Roma'y el Centre Cívic Ca n'Amiguet? Ninguna, es que no sé.... pero relación de... no. [...] Porqué este espacio yo veo que viene más la gente mayor, bueno... está separado totalmente, y alli estamos la gente joven. Es como... y creo que es por eso. Yo creo que está bién como está, yo creo que está bién, sí. Jennifer, barrio de La Romànica, 22 años. Vive en el hogar familiar y estudiante universitaria, no tiene trabajo remunerado. Nacida en Sabadell (Catalunya).
\end{abstract}

Y después ya el tema jóvenes, el casal de jóvenes... no hay mucho contacto. [...] Además había mucho miedo por que hubiera mucho jaleo en el barrio, porqué había mucha gente mayor. Júlia, barrio de La Romànica, 52 años. Casada con un hijo emancipado, tiene trabajo remunerado. Originaria de Sant Quirze de Besora (Catalunya).

\section{Sobre la Identificación Con el Barrio}

Lo que destacaría en general en las entrevistas es el cierto equilibrio, ligeramente a favor de las primeras, entra las mujeres que se identifican con el barrio, y expresan su identidad de barrio, con las que no:

Es un sentimiento que está, lo tiene todo el mundo. No, és que, no, no te podría decir, somos de La Romànica, y La Romànica es como una cosa muy nuestra, es una parte nuestra, es, como digo yo, una tarjeta de presentación. [...] Una tarjeta de presentación la puedes hacer más bonita o más fea, si la haces como una cosa propia cada vez la irás puliendo más... y yo creo que esto es una de las cosas que hemos hecho entre todo el mundo, ¿no? me da la sensación. Júlia, barrio de La Romànica, 52 años. Casada con un hijo emancipado, tiene trabajo remunerado. Originaria de Sant Quirze de Besora (Catalunya).

Yo lo digo, yo vivo en Ca n'Anglada y ningún problema, pero sentirme identificada no... es mi barrio y ya está, pero no tengo ninguna devoción, podría cambiarme perfectamente, porqué como no tengo el grupo de amigos podría irme perfectamente a otro barrio y encontrarme igual de bién. Rosana, barrio de Ca n'Anglada, 27 años. Vive en el hogar familiar, estudia y tiene trabajo remunerado. Nacida en Terrassa (Catalunya).

En el caso de las mujeres que se sienten del barrio, destacarían las referencias al pasado, donde los aspectos de autoconstrucción de casas y del propio barrio, así como la lucha vecinal son reiterativas, así como valorar la propia escala de los barrios, donde todo es cercano y accesible:

Sí que hay ese carácter de barrio, sobre todo gente de mi edad, que los ves aquí, ellos si que hablan y hablan "así, te acuerdas cuando hicimos lo del de eso...". La Plaza Catalunya por ejemplo fue una de las plazas que les hablarás y que les sabe mal que no esté dentro de su barrio, porqué costó mucho, costó mucho y fue de aquellas batallas fuertes eh! y el Agustí Bartra fue otra cosa igual. $Y$ hay mujeres que eso lo tienen como algo suyo y esas no son las que se van desde luego. Y la plaza, la plaza en los años aquellos era... a parte aquí en los años setenta y siete arrasó el PSUC, es que la gente estaba muy politizada, es que era aquí que podíamos hacer algo, aquí y en 
otros barrios. Aquí habían presos políticos e ibas a buscar dinero y todo el mundo con miedo o sin miedo, ahora pienso "no lo sé", pero todo el mundo daba dinero. Yo sé gente que ha estado en busca y captura y ha estado en casas de aquí. Pepi, barrio de Ca n’Anglada, 50 años. Casada con un hijo emancipado, tiene trabajo remunerado. Nacida en Terrassa (Catalunya).

Por otro lado, las que no se consideran identificadas con sus respectivos barrios, destacan los casos que lo relacionan con la presencia y asentamiento de nuevas vecinas y vecinos de origen extranjero:

Nada [...]. Encuentro que la gente... esto, este trozo, Duquessa de la Victòria, Bages, Concepció Arenal por aquí, lo encuentro como muy pueblo, y además, hay tanta inmigración... la inmigración, yo no estoy en contra de que vengan, pero que se adapten. Sobre todo socialmente, y no. No hay respeto. $Y$ esto de la inmigración, hay mucha suciedad porqué son ellos. Cesca, barrio de Can Palet, 54 años, separada con un hijo y dos hijas mayores de edad, de baja médica. Originaria de Almería (Andalucía, España).

En relación a las referencias a sus lugares de origen, destacaríamos el apego al lugar donde se ha nacido y desde donde se hizo el proceso migratorio hasta Catalunya, con el reconocimiento al lugar y sociedad donde se instalaron -aunque no siempre- expresándose así un sentimiento de catalanidad, se hable o no la lengua catalana. En el caso de mujeres que han inmigrado recientemente esta identificación seria mucho más débil o no se expresaría, pero queremos remarcar que son mujeres que han manifestado la necesidad de tiempo, un tiempo que tiene claro que será más accesible para sus hijas e hijos:

Ha hecho tantos dineros esta señora que ya se le ha ido la... dice "yo quiero ir a Sevilla $y$ mis tres hijos no quieren venir", claro, ya los tres tienen su vida aquí. Yo soy de Sevilla, pero jo me siento catalana. Si son segundos lo que estamos aquí viviendo por qué tenemos que tener esta cosa, "soy de Sevilla", si son los primeros... nosotros cuando venimos aquí... cuántas personas son de la misma... de Sevilla, de Córdoba, de todo, de Almería, no se han integrado aún, y vinieron aquí cuando yo, y no se quiereni integrar. Porqué yo digo, bueno, yo tampoco hablo bién el catalán, yo he querido integrarme ¿a que han sido las personas que a mí me han acogido? me han abierto ellos... pero cuantas personas hay que dicen "no, no, yo catalán ni hablar". No, no, muchas personas no quieren. ¡Ah! que no digan que esta gente han venido $y$ no se quieren integrar. Mónica, barrio de Ca n’Anglada, 67 años. Ví-dua, con dos hijas, una emancipada y la otra dependiente. Originaria de Sevilla (España).

Hombre, por la fuerza tenemos que sentirnos de aquí, porqué sino... yo por lo menos mi caso, me siento, porqué si dejo de sentir este sitio no sé como sería. Yo no, yo, yo... yo aquí estoy y estoy con todo, lo mismo el cuerpo que el alma, tú. Estoy aquí [...]. Vivir separada en un sitio, partida, no tiene sentido. Fátima, barrio de Can Palet, 39 años. Casada con hijos, no tiene trabajo remunerado. Originaria Ksar-el-Kbir (Marruecos).

Más minoritariamente se expresan opiniones favorables a la identificación con la ciudad, o al fomento de una identidad de ciudad por encima de la de barrio, expresada por personas jóvenes, que ponen de manifiesto formas diferentes de vivir y expresar el arraigo e identificación con el lugar entre generaciones:

[Íngrid] Es que como somos jóvenes y nos movemos mucho pues el barrio no... Però de Terrassa sí que us sentiu, no? [Marta] Terrassa sí, porqué te mueves entre varios barrios de la ciudad, entonces eres un poco de todos lados. Íngrid, barrio de Can Palet, 16 años. Vive en el hogar familiar, estudiante de bachillerato. Nacida en Terrassa (Catalunya) / Marta, barrio de Can Palet, 17 años. Vive en el hogar familiar, estudiante de bachillerato. Nacida en Terrassa (Catalunya).

Relacionado con este apartado, tendríamos que tener también presentes las opi-niones entorno a la integración al lugar, donde algunas mujeres exponen, presuponiendo, que las personas de origen extranjero en el barrio no tienen interés en integrarse: 
Ummm, no, realmente no. Ahora, no se integran, están mucho en su mundo también. Doris, barrio de La Romànica, 70 años. Casada con hijos mayores. Originaria de Palma del Río (Córdoba, España).

Como contrapunto, las mujeres recién llegadas muestran su predisposición y ne-cesidad de integrarse, comentándose de nuevo aspectos relacionados con la lengua cata-lana:

Pués, no sé, yo por ejemplo, mi tía ahora está... también hace poco, 3 años que está aquí en Terrassa y aún no... si le hablan ella sabe el que le están diciendo. Después tengo otros tíos que les cuesta también un poco, pero como más o menos todos llegaron hace tiempo como mi madre, la gente más o menos ya sabe hablar catalán y todo. Sí hay algunos que nos dicen "lo tengo que aprender porqué estoy aquí y, claro, si tengo que trabajar en cualquier sitio y me piden hablar en catalán pués para defenderme y tal" pero hay algunos que vienen y como si aprendieses otro idioma también. Chloe, barrio de $\mathrm{Ca}$ n'Anglada, 19 años. Vive en el hogar familiar, estudia. Nacida en Terrassa (Catalunya).

En relación a la integración, también destacar, que algunas mujeres hayan re-señado el papel de la escuela como crucial para generar procesos de integración y cohe-sión comunitaria:

Eso es una cosa lenta, que yo creo que lo primero es meter a sus hijos en las escuelas y a las madres intentar ayudarlas de una manera u otra. Pepi, barrio de Ca n’Anglada, 50 años. Casada con un hijo emancipado, tiene trabajo remunerado. Nacida en Terrassa (Catalunya).

Al mismo tiempo, y para el caso de mujeres de origen español y de origen ex-tranjero que han llegado ya adultas a sus respectivos barrios, se pone de manifiesto las dificultades que han tenido por el hecho de venir ya mayores -unas díficultades que con-sideran que sus hijos e hijas no tendrán- remarcando el tema de la lengua y la débil red social, aunque algunas resaltan al mismo tiempo la existencia de solidaridad y apoyo vecinal autóctono para salir adelante, así como la necesidad de tiempo para adaptarse al lugar:
No lo sé, yo no tengo amigos ni vecinos, nada, porqué no he tenido la oportunidad, sí que si bajo "hola" y "qué tal" y me hacen algú comentario, pero que así de amistad no, porqué no, parece ser que... no sé, que la gente de aquí no, no hay mucha vecindad o a lo mejor es porqué tengo muy poco tiempo, no lo sé, y además a mi tampoco me gusta, me gusta "hola" y "qué tal" pero no estar ahí mucho tiempo, no tengo tiempo. Esperanza, barrio de Ca n'Anglada, 52 años. Casada con hijos emancipados, no tiene trabajo re-munerado. Originaria de Granada (Andalucía, España).

Al principio fue muy duro, porqué te dejas la familia, la madre y tal. Pero después de pasar siete años ya me he acostumbrado aquí más. Me estoy acostumbrando a poco a poco. Suleima, barrio de Can Palet, casada con un hijo, tiene trabajo remunerado. Originaria de Ksar-el-Kbir (Marruecos).

\section{Sobre El Asociacionismo y Espacios de Participación de Mujeres}

Lo primero que destacaríamos sería la importancia de la proximidad y, por tanto, la escala de barrio, en la participación asociativa que expresan las mujeres entrevistadas, ya que de forma mayoritaria la vinculación a espacios asociativos de carácter comunita-rio, y vinculados a las mismas áreas de residencia, $\mathrm{o}$ en actividades promovidas en equipamientos municipales de barrio:

Es fácil, me levanto a las ocho, desayunamos, traigo a la niña al colegio, lo clásico que hace la mujer, vas de compras, estás en casa hasta las doce que tengo que venir otra vez a buscarlas, la comida, come. A las tres vuelve al colegio, de tres a cinco, depende, normalmente estoy en casa, a mi me gusta mucho la informática y estoy con mi ordenador, y a las cinco, cuando sale la niña, vengo a buscarla, entonces ya estoy aquí haciendo las cosas del APA [Asociación de Madres y Padres de Alumnos y Alumnas], ir poniendo al día los recibos, y cosas así, por si hay algún problema. Esa es mi vida. Por la noche llego a casa, ceno, la tela y a dormir. No es muy sofisticada. [...] El fin de semana, al menos, ya no tengo que venir al colegio. 
Después, bueno, mi marido trabaja y tampoco es... el sábado no es algo especial. Ahora mi hija va al esplai, pues la llevo al esplai y después estoy en casa. Y el domingo es el día que haces... a veces no haces nada, pero te vas a pasear, por ejemplo. Mar, barrio de Ca n'Anglada, 37 años, casada con una hija, no tiene trabajo remunerado. Originaria de Velilla de Cinca (Huesca, España).

Lo segundo que tendríamos que destacar es que mayoritariamente las mujeres entrevistadas, cuando se vinculan a espacios asociativos, lo hacen en colectivos o enti-dades no estrictamente de mujeres o feministas. Tratándose de espacios que sí que res-ponden, como hemos dicho, a criterios de proximidad, del propio barrio, y del ámbito de la acción social y comunitaria:

Yo me quedé viuda hace 10 años, y claro, entonces yo estaba... [...] y al cabo de un año y medio, mi cuñada empezó "¿por qué no salimos?" y entonces empezamos a venir a las excursiones. Entonces fue cuando me dijeron que me pusiera con la asociación de personas mayores [...]. Yo nunca he sido de esto, nunca he ido a ningún lado, y nunca he hecho una vida de éstas de ir a sitios a ayudar ni nada, no lo hecho nunca, la verdad. $Y$ al final me engañaron [rie] y me puse. Reconozco ahora, pués esto que te decía, tengo más amistades, porqué yo antes iba por la calle y, escucha, si nos saludábamos era porqué nos encontrábamos en la tienda "¡hola! Buenos días" "Adios", y punto, y ahora en cambio tengo una relación más bonita con mucha gente, con muchas personas del vecindario. Meritxell, barrio de Can Palet, 71 años. Viuda, vive sola. Nacida en Terrassa (Catalunya).

Yo estoy en la asociación de comerciantes del barrio La Romànica. Bueno, somos 4 gatoss jeh!, porqué la gente no viene a las reuniones. En esto me refiero que la gente no se acaba de querer meter un poco más y ponerse serios, que a ver, que estamos en el 2011, ¿sabes? Esto les toca un poco a la gente del barrio que tiene negocio porqué son negocios de toda la vida que han ido haciendo y que se han ganado bien la vida y que ya están bién como están y, a lo mejor, hay un sector que nos gustaría promover un poco que se moviera de otra manera. Sandra, barrio de La Romànica, 35 años. Casada con un hijo, tiene trabajo remunerado. Nacida en Sabadell (Catalunya).

En todo caso, destacar que, aunque muy minoritarias, sí que se han expresado experiencias y posicionamientos que tendríamos que situar en el feminismo político y activista, donde la participación de mujeres en espacios asociativos tiene una motivación en interés por transformar el papel de la mujer en el tejido asociativo:

El hecho de la poca presencia... y me motivó a decir " a ver, es que aquí tiene que haber alguién más” y, bueno, cosas como "la actividad del grupo de mujeres, hacer tortillas" dices, ihombre! ¿la actividad del grupo de mujeres que l'associació proposa, que sigui fer truites? es que no. $Y$ comentarios y actitudes que dices " a ver, ¿sólo pueden hacer tortillas las mujeres?”, no, vale. Pero mucho ir marcando esta pauta, que no la tenían nada clara. La correspondencia, las actividades, ir marcando un poco más por esta banda, más de tener en cuenta las dos partes a la hora de organizar actividades, a la hora de todo un poco. La chocolatada infantil... "¿qué madres vendran?", no, no, escucha, para mover una olla tan buenas son las madres como los padres, y cosas de estas que te iban enfadando bastante. Y entonces, bueno, he ido un poco por este camino. Bea, barrio de Can Palet, 31 años, vive con su pareja, tiene trabajo remunerado. Nacida en Terrassa (Catalunya).

En tercer lugar, de forma destacable se reconoce y se remarca abiertamente el papel de las mujeres en la mejora de los barrios a través de su implicación directa en actividades o en la lucha vecinal de base; en el dinamismo del asociacionismo de barrio y en la propia vida cotidiana como importantes agentes de socialización y de relación comunitaria en sus respectivas áreas de residencia:

Por ejemplo el colegio este de aquí fue unas luchas fuertes, hasta con los famosos grises y todo eso. Eran reivindicaciones de barrio, chocolatadas, fiestas, festivales, y eran unas reivindicaciones muy duras y muy llevadas por las mujeres, porqué claro la 


\begin{abstract}
parte técnica y de control la llevaban las mujeres y no mujeres particularmente de partidos ni nada de eso, no, no, mujeres de asociación de vecinos, del barrio. Pepi, barrio de Ca n’Anglada, 50 años. Casada con un hijo emancipado, tiene trabajo remunerado. Nacida en Terrassa (Catalunya).
\end{abstract}

En cuarto lugar, opiniones en relación al proceso de institucionalización de es-pacios y políticas de igualdad o destinadas a mujeres también se han puesto de manifi-esto de forma destacable, aunque no mayoritariamente. Destacarían las opiniones críticas con el proceso y el hecho de ver la creación de grupos y colectivos de mujeres desde los ayuntamientos como restrictivo y poco flexible para el conjunto de mujeres:

Es que yo creo que lo de Dones de Ca n'Anglada es de gente mayor, yo ahí no conozco a nadie joven, yo ya no sé si es dedibo o por falta de tiempo, por qué, pero conozco gente de allí de la Dona y son todas mayores, entonces ni sé como funciona,... sí, una vez hace mucho tiempo fui a un cursillo de cocina, porqué era un horario que podía y me hizo gracia y fui, fueron dos o tres clases, pero que más bien es gente mayor las que van. Lucía, barrio de Ca n'Anglada, 37 años. Casada con un hijo, tiene trabajo remunerado. Nacida en Terrassa (Catalunya).

Supongo que hay todo el tema de la consejería de la mujer, pero... y lo de la Casa Galèria, pero esto de los barrios queda un poco lejos. La mujer que está motivada va hasta allí, pero en los barrios nos queda bastante lejos, $i$ yo en Casa Galèria me meto, voy y hago, pero la mujer de cada día, de casa, no lo conoce. Bea, barrio de Can Palet, 31 años, vive con su pareja, tiene trabajo remunerado. Nacida en Terrassa (Catalunya).

En todo caso, algunas opiniones expresa el hecho que la misma creación de es-pacios de relación entre mujeres, aunque no tengan una politización feminista, ya es po-sitivo en el contexto actual:

Al principio no lo vi muy claro, lo digo sinceramente, el trabajo del colectivo de dones para enseñar flores, plancha, macetas y eso, entonces al no verlo claro yo no he estado ahí, pero bueno como veo que están haciendo un trabajo estupendo de aglutinar de una manera u otra o mover a la gente, yo diría que a casi quinientas mujeres del barrio, es muy importante, que aunque vayan principalmente para hacer yoga y para aprovecharse de todas esas cosas alguna cosa les queda y, a veces, se hacen charlas de este tipo, charlas dedicadas a medicina, problemas cívicos o de abogados y cosas de esas. Cuesta un poco mover, las quinientas no te van pero si te van ochenta, si te van setenta pues ya es un éxito y eso es lo que hacen. Y la verdad que "chapeau", lo hacen muy bien y son unas cuantas mujeres que trabajan mucho y que trabajan muy bien. Pepi, barrio de Ca n'Anglada, 50 años. Casada con un hijo emancipado, tiene trabajo remunerado. Nacida en Terrassa (Catalunya).

También se ha valorado el hecho de si han habido cambios o no en relación a as-pectos de igualdad y no discriminación a las mujeres, y se han expresado tanto opiniones positivas como más pesimistas, remarcando el hecho que la experiencia vivida en los últimos años muestra una combinación entre procesos de avance y retroceso, vinculados, sobre todo, al tema de la vinculación y supeditación al hogar en relaciones de pareja entre hombres y mujeres, y generaciones jóvenes:

Yo estuve 13 años en la política, y vale. Era entre compañeras políticas, más o menos, piensas, hay el discurso [...] pero mi sorpresa al volver a entrar en enseñanza y ver que las compañeras de sufrir corriendo para llevar al niño al médico, que las compañeras eran las que tenían que sufrir porqué tengo el niño malo, porqué se tiene que hacer esta gestión en el banco. Ostras, no hemos adelantado nada. Los tíos continúan sin tener que plegar ellos más deprisa, para eso no valía la pena hacer tantos discursos [...]. El tema es de mentalidad y de libertad, y de respetarse, si hay convivencia de pareja pués de repetarse uno a la otra estos espacios de libertad. Ahora, mientras eso no se entienda así ya podemos ir haciendo discursos de "nosotras parimos, nosotras decidimos", y no, no se gana nada demasiado. Y después, yo pienso que el tema de la igualdad de la mujer, a ver, mientras la publicidad 
continue utilizando el cuerpo de la mujer objeto y las mujeres se vayan prestando y mientras sigamos víctimas como somos de la moda, está bién que hayan modas, porqué si no sería muy aburrido que toda la vida todo el mundo fuera igual vestido, pero este 'delirium' de ir al punto y ir mona, bueno, es exagerado, com es exagerado todo el... es aquí donde tenemos el problema, no es en el urbanismo ni en los centros cívicos si nos dejan hacer macramé. Para mí el tema está más en toda la sociedad de consumo. Eulàlia, barrio de Can Palet, 59 años. Casada con hijos mayores de edad, tiene trabajo remunerado. Nacida en Terrassa (Catalunya).

Sí, sí, yo creo que sí. Las mujeres ahora se ven con más iniciativa y que tiran más en esto... yo sí que lo creo... comparando con las otras... porqué las de antes eran muy trabajadoras pero no tenían aquello de decir... chillar o dar... ahora se hace de otra manera. Por ejemplo, con los hombres mismo, antes... que yo encuentro que ahora se están pasando también... ni antes ni ahora, porqué ara te chilla un hombre y dice "vale, a tú casa" y eso tampoco es. Pero antes una mujer trabajaba e iba a su casa, y decía "buena, pués ala! tengo que fregar" y el otro decía "yo me voy a tomar una cerveza, y tú friega”. Y ahora pués las mujeres llegan a su casa y dice "yo hago esto, si lo hago, y si no pués se quedará sin hacer", cosas así, es verdad. Montserrat, barrio de La Romànica, 59 años. Casada con dos hijas no emancipadas, tiene trabajo remunerado. Nacida en Sabadell (Catalunya).

\section{Sobre Demandas y Políticas de Barrio}

En general, lo que destacarían en el ámbito de las demandas que se expresan es el cierto equilibrio entre las mujeres que consideran necesarias políticas de barrio vincu-ladas a temes sociales y comunitarios, y las que consideran más oportunas políticas de barrio vinculadas a una reforma urbanística estricta, siendo algo más favorables a las primeras. En muy pocos casos se ha expresado la necesidad de combinar unas y otras. Al mismo tiempo es muy débil el conocimiento sobre políticas institucionales destinadas a los barrios y, por consecuencia, una valoración de las mismas, aunque se hayan expresado algunas opiniones al respecto:
Sí que se hacen, pero son iniciativas muy... como te lo explicaría... es muy iniciativa personal de cada uno. Es iniciativa del educador que está en 'Dis-tricte Jove', es iniciativa de la educadora de Servicios Sociales, pero desde lo que es la política no, es que yo no encuentro ninguna puesta marcha, ningún dispositivo para ayudar a la gente, para dar caña, dar pasta, dar pasta a servicios sociales, dar más recursos, que van de culo. Lo encuentro muy fuerte, no me estoy metiendo con los trabajadores que son los únicos que están haciendo cosas, si no que me estoy metiendo con la gente que está decidiendo, y con la gente que está gestionando un poco esto, que lo están gestionando con el culo. Ona, barrio de Ca n'Anglada, 22 años. Vive en el hogar familiar, tiene trabajo remunerado. Nacida en Terrassa (Catalunya).

A ver, seguramente habrá muchas carencias pero no sé ahora mismo no... [...] Bueno, sobretodo a nivel accesibilidad, que es lo que se quejaba mucha gente por las aceras y tal... las casas son muy antiguas y ahora con el lavado de cara que se le está dando al barrio, creo que eso ya no hace falta... no es el barrio de hace dos años. Laura, barrio de La Romànica, 32 años. Vive en el hogar familiar, tiene trabajo remunerado. Nacida en Sabadell (Catalunya).

Pero cuando se entra a concretar estas propuestas, la concreción es más rica y abundante en el caso de las mujeres que se muestran más favorables a temas de carácter social y comunitario, así como a temas vinculados a necesidades específicas para el co-lectivo de mujeres o colectivos concretos, como los jóvenes o personas mayores. En este sentido destacarían las demandas de espacios de relación y encuentro en materia de equipamientos, con flexibilidad horaria, para mujeres y jóvenes; una política de centros educativos integral en la etapa obligatoria en el mismo barrio (pasar de la escuela al ins-tituto en el propio barrio); residencias para personas mayores; así como programas de carácter comunitario para fomentar las relaciones sociales en el barrio, la integración y cohesión o promover pautas y procesos de socialización en lo colectivo y político y ac-tividades en la propia calle con y para la juventud: 
Siempre se quedan las cosas en las propuestas, hay o no hay dinero. Desde Casa Galèria se gestionó un proyecto el año pasado de manualidades, que enseñaron la pintura en la tela, sí que funcionó, pero todavía está bloqueado porqué el tema de dinero siempre se queda en medio, y tiene un local aquí, quiero decir que lo podemos aprovechar para más cosas. [...] A mi me gustaría, porqué siempre trabajo con la escuela, me gusta que la escuela funcione mejor, porqué me parece que es la base de la integración. Y como las madres tienen la barrera del idioma y uno no puede estar en todas partes, vas allí... hay algunas madres que ya hablan y sí que se espavilan, pero lo de participar en la asociación pués no. Sara, barrio de Ca n'Anglada, 29 años. Soltera, tiene trabajo remunerado. Originaria de Ksar-el-Kbir (Marruecos).

En cambio, las opiniones favorables a la reforma urbanística, se quedan en un posicionamiento generalista en esta materia, y de forma residual se hace referencia a la necesidad de limpieza en las calles:

Poner papeleres, barrer, porqué es horroroso. Yo la acera de la tienda cada dos días la tengo que barrer porqué está llena de botellas, de paquetes de tabaco. A ver, es un problema de la gente también, yo no digo que sea un problema de... pero a lo mejor en vez de una persona a la semana que pasen dos o tres veces a la semana a barrer las calles. Ariadna, barrio de Ca n’Anglada, 24 años. Vive en el hogar familiar, tiene trabajo remunerado. Nacida en Terrassa (Catalunya).

Como contrapunto, y que consideramos interesante, sería la mención que hace una entrevistada por patrimonializar el legado constructivo de carácter popular en los barrios, pensando en la existencia de 'casas baratas' (casa inglesa para obreros) y casas de autoconstrucción, como un legado a proteger y promocionar como propio de este tipo de barrios:

Yo siempre he pensado que el Carrer Colom, por ejemplo, el trozo que quedaba se tenía que conservar como realidad históricoa de Terrassa, como realidad obrera, pero se ha saltado bastante. El ayuntamiento lo que no son pelas son puñetas [...] Quiero decir que... este es el proceso histórico que ha hecho el barrio, que estamos en pleno cambio y acabaremos comiéndonos un barrio que era... que todos nos conocíamos, que era muy de pueblo. No lo sé, a lo mejor porqué he crecido, porqué, bueno... pero era muy nuestro, mиy conocido, que sabías quien vivía en cada casa, todo el mundo nos conocíamos. Bea, barrio de Can Palet, 31 años, vive con su pareja, tiene trabajo remunerado. Nacida en Terrassa (Catalunya).

En relación a las referencias sobre el conocimiento y participación en políticas desarrolladas desde administraciones públicas en los respectivos barrios, tenemos que decir que no han sido mayoritarias las que expresan un conocimiento claro $\mathrm{y}$, aún menos, que hayan participado. En este sentido, tendríamos el cas de los llamado "Plans de Barris"3 (NELLO, 2009), con una incidencia directa en dos de las áreas de estudio (Ca n'Anglada y La Romànica), pero que, como decimos, a parte de unas pocas referencias que expresan conocimiento y participación, otras tienen noticias muy generales sobre este programa de actuación en los barrios desde el sector público. Al mismo tiempo, también destacaríamos que algunas de las actividades comentadas están dirigidas a mujeres muy concretas y restringidas a una tiempo limitado, poniéndose de manifiesto las limitaciones de su incidencia comunitaria y social, tanto a nivel colectivo, como mujeres, y a nivel de lugar, como barrio, aunque originalmente la voluntad de las administraciones públicas implicadas sería incentivar la participación:

Sí, se hizo una especie de reunión y presentaron la maqueta, lo presentaron al barrio el proyecto, pero discutir no. Eso ya estaba decidido. Pero bueno, presentárselo a los abuelos, y "mira cuantas cosas vamos a hacer”, pero eso hace muy poco. Ona, barrio de Ca n'Anglada, 22 años. Vive en el hogar familiar, tiene trabajo remunerado. Nacida en Terrassa (Catalunya).

Eran actuaciones más dedicadas y diseñadas por las mujeres del barrio en función del perfil que tuvieran, de las edades, de las necesidades que detectáramos... ¿Qué ha pasado en estos años? Pues que hay unas actuaciones y señales, pero a grandes rasgos eran muy genéricas y realmente este año se ha absorbido tanto el tema de la remodelación urbanística, con la ayudas que hemos dado a los vecinos para remodelar edificios. Lourdes, técnica municipal, barrio de La Romànica. 
Yo sí que estuve participando en un taller aqui mismo. Se estuvo organizando para el desarrollo de las mujeres extranjeras, que se estuvo organizando aquí...estuvo muy bien. A mi no me faltaba tanto pero por ejemplo para la gente marroquí y para las chicas de Sudamérica, de África, de todo eso... sí que lo... Se lo pasaron bien y se quedaron con algo de ese taller. La mayoría eran mujeres de aquí del barrio y de Barberà también que como lo ha hecho, lo ha hecho la Cruz Roja de Sabadell pero por Barberà nos juntaron a todas y se hizo aquí en el barrio. ¿Se consiguió algún tipo de iniciativa para que os siguierais reuniendo o que hubiera la posibilidad de crear...? No sé, yo por mi parte, sí... pero había chicas que lo estaban comentando también que le daba miedo que le van a quitar la ayuda si se presentan al cursillo. Algunas sí, algunas sí pero todas no. ¿Tuvo continuidad el proyecto para el grupo de mujeres que participasteis? No, no, no. Maria, barrio de La Romànica, 35 años. Madre separada con una hija, actualmente en el paro. Originaria de Trugmuresh (Rumanía).

Con lo expuesto en este apartado, observamos como diferentes dimensiones o temáticas de análisis, teniendo en cuenta lugares y colectivos que podrían responder a ámbitos urbanos y sociales más o menos homogéneos, son vividos y percibidos de forma diversa y múltiple, en este caso por mujeres, pero como pasaría con otros colectivos, poniendo de manifiesto la importancia e interés de partir de una concepción interseccional de los fenómenos socioespaciales.

\section{Recapitulando entorno a la experiencia vivencial de mujeres en el barrio: dinámicas en positivo y dinámicas en negativo}

Sobre las dinámicas en positivo, resaltaríamos los avances en la autonomía personal y colectiva de las mujeres y el propio papel de las mujeres en la vida cotidiana y comunitaria de los barrios estudiados (YEOH ; HUANG, 1998; LEE, 2007; VAIOU, 2010). $\mathrm{Y}$ un dato a destacar en este sentido sería la elevada participación asociativa o en actividades de buena parte de las mujeres entrevistadas, incorporándose a espacios asociativos desde opciones no politizadas y, en menor medida, desde posicionamientos feministas.
Creemos que es el aspecto que rompe claramente con el pasado, ya que mujeres mayores ya nos hablan de sus largas jornadas en empresas téxtiles o metalúrgicas y el mantenimiento de las tareas domésticas, como ahora siguen haciendo otras mujeres de generaciones más jóvenes en otros ámbitos laborales. Y tanto antes como en la actualidad no son pocas las que abandonan o adaptan el trabajo remunerado para centrarse en el cuidado de hijos e hijas y el hogar en general. Lo novedoso de lo que trasmiten las entrevistas sería la elevada implicación activa en asociaciones o en actividades asociativas, ya que son muy pocas las mujeres que lo hacían en el pasado -al menos en lo expresado en las entrevistas. Eso sí, no tenemos que olvidar el papel fundamental que jugaron muchas mujeres, a menudo silenciado en favor de los espacios representativos y dirigentes masculinizados, en la organización y desarrollo de actividades y acciones reivindicativas en el barrio para reclamar mejoras, un aspecto que también se ha puesto de manifiesto en mujeres con las que se ha entrado en contacto. Estas experiencias han existido y esas mujeres existieron $\mathrm{y}$ existen y hay que reconocerlo, y estudiarlo. Es por eso que podríamos hablar de un "tercer tiempo" o "tercer espacio" en el caso de muchas mujeres residentes en barrios populares, donde, a pesar de todo, han sacado tiempo para relacionarse, participar y asociarse.

En todo caso, esa implicación asociativa tiene muy poca fluidez e interacción con la acción política más institucional, la de las políticas de barrio o concejalías de mujeres o de igualdad, donde ha prevalecido el intervencionismo de arriba abajo, movilizando más que organizando, y muchas veces pasivamente, a pocas mujeres de estos barrios. En el ámbito de la acción política no institucional, la vinculada al feminismo activista y reivindicativo, aún las conexiones son más débiles, por no decir inexistentes. Sin olvidar que la mayoría de estas mujeres no se implican en los espacios asociativos comentados por motivaciones de carácter político o feminista, y esto también hay que tenerlo en cuenta.

Pero la experiencia vivencial también nos pone de manifiesto un aspecto propio de sus vidas cotidianas y es la utilización de espacios más íntimos para relacionarse y socializarse (BLUNT, 2005; CHRISTIE, 2006), evitando los tradicionales espacios públicos o combinándolos, que pueden ser vistos $\mathrm{y}$ vividos como restrictivos y de vulnerabilidad (HYANS, 2003; MERRIL, 2004; REID, 2008). Esta naturalidad en la hibridación y tránsito que ejercen las mujeres en su vida cotidiana entre espacios que tradicionalmente se han visto como fragmentados entre lo público y lo privado, es un aspecto a tener en cuenta en nuestra forma de trabajar, analizar y actuar 
(LONGHURST, 2006) que muchas veces es un problema de concepción eurocéntrica (ARRIF, 1997; MONQID, 2001; NAVEZ-BOUCHNINE, 2001; MILLS, 2007).

En el caso de lo que hemos considerado como dinámicas en negativo, el primer aspecto donde haría falta detenerse es en el papel que tanto el hogar, como el trabajo fuera de él, juega en la vida de las mujeres entrevistadas. La vinculación a las tareas domésticas y a las hijas e hijos es lo más corriente y, si alguna cosa se debilita, es la presencia de las mujeres en el mundo del trabajo asalariado, manteniendo sus respectivos compañeros o maridos sus trabajos. Es una realidad que han explicado mujeres mayores, algunas con amargura, pero también mujeres jóvenes, llegando al punto de considerarlo normal y propio y exclusivo de mujeres, mostrándonos una realidad para las mujeres donde los avances en aspectos como la representatividad institucional y en el mercado laboral coexisten con claras resistencias, cuando no regresiones o reforzamientos de la desigualdad y la discriminación que hay que reconocer (GLESON, 1995; BONDI; DOMOSH, 1998; PAIN ; TOWNSHEND, 2002; RODRÍGUEZ ; ARAYA, 2003; KERN, 2005; URÍA, 2009).

Al mismo tiempo, y en tono de reconocimiento y denuncia -y ya es importante, creo, que ellas mismas lo hayan expresado- se habla de cómo desde el ámbito familiar se ejerce un control sobre ellas desde pequeñas y una diferenciación discriminatoria respecto los hermanos. Podríamos considerar que estas situaciones, junto con el posicionamiento negativo que se muestra respecto a las personas inmigradas, son las que muestran líneas más regresivas o conservadoras en lo que avance social y comunitario se refiere, tanto para el sujeto mujer como para los respectivos barrios.

En todo caso, y para acabar este apartado que, como se ha dicho, es el que muestra una realidad más regresiva, reseñar que el posicionamiento de las mujeres autóctonas respecto las personas inmigradas en los barrios se correlacionan, de forma considerable, con el hecho de tener o no tener relaciones habituales y cotidianas entre ellas. Es decir, las mujeres de diferentes orígenes que mantienen relaciones habituales entre ellas, son las que nos hablan desde la normalidad, y las posiciones más cerradas y negativas reconocen que hablan desde, al menos, el desconocimiento vivencial y relacional con personas inmigradas. Por eso sería más acertado hablar de prejuicio o estereotipo étnico o culturalista. El posicionamiento etnicista y estereotipado también se expresa cuando se habla de miedo a los espacios masculinos o sobremasculinizados (sobre todo en la calle), pero aquí habría que tener en cuenta procesos de control social sobre el sujeto mujer, tanto en el ámbito familiar como la misma presión de miradas o comentarios de hombres. En este sentido, sería más oportuno hablar del hecho de evitar espacios con presencia masculina o sobremasculinizados (que han expresado tanto mujeres inmigradas como autóctonas, y no todas vinculándolo a un tema étnico). Así, además de pensar en prejuicios y estereotipos, hace falta que nos centremos también en las consecuencias de ejercer un control social a partir de la atemorización en general $\mathrm{y}$, en particular, sobre el sujeto mujer, debilitando libertades y autonomía personal (RUDDICK, 1996; MADGE, 1997; KOSKELA, 1997 ，1999; DAY, 2001, VALENTINE, 2001) donde aspectos vinculados a la construcción de la masculinidad son esenciales para entender $\mathrm{y}$ combatir estos procesos.

\section{Interacción entre proceso investigadory mujeres de barrio. Pasando de las carencias a los nuevos retos}

En los apartados anteriores nos hemos centrado en una revisitación de la fuente oral generada a través de entrevistas en profundidad a mujeres de tres barrios humildes. Hemos apuntado que existe escasa fluidez o nula entre la implicación asociativa de mujeres y el mundo de la política institucional y la no institucional en temas de mujeres y en temas de barrio. Sin olvidar que, al margen de pautas generales que han sido expresadas en las entrevistas, sobre las que tenemos que luchar para cambiarlas, como la reproducción de estereotipos culturalistas o la mencionada poca sintonía entre lo político (institucional o no) y "la calle", son aún muy destacables otras pautas de discriminación y control social que afectan estrictamente a las mujeres, y que más que superadas siguen reproduciéndose cotidianamente y generación tras generación. Pero constatadas estas dinámicas ¿qué fluidez ha existido entre lo académico y las mujeres de estos barrios? ¿cómo se ha influido a partir del proceso investigador?

En el caso estricto de los procesos de investigación que en este trabajo se están tratando, y sobre todo para las dos primeras áreas de estudio, si bien ya suponían un primer puente de interacción entre el mundo académico y mujeres de estos barrios, la realidad también es de escasa o nula fluidez entre este ámbito. En este sentido, si bien en algunas entrevistas las mujeres nos han resaltado el hecho de hacerles pensar en temas sobre los cuales no habían pensado y tendrían en cuenta a partir de entonces, habiendo contribuido ya una cierta reversión y cambio personal, 
o en el propio trabajo de campo se ha podido poner en marcha una participación más directa por parte de la investigadora, el resultado es, en general, de una escasa interacción. Así, el propio proceso de investigación en general, en relación a los dos primeros proyectos que dieron lugar a la Tesis Doctoral, es una muestra más de lo que yo mismo estaba criticando. Mi proyecto académico en sí había funcionado y había actuado de la misma forma que los proyectos institucionales desarrollados en los mismos barrios: aparecer, para desaparecer. Desvanecerse todo lo hecho en las áreas de estudio en el mismo momento de acabar el trabajo de campo. Al mismo tiempo, el trabajo de campo se fundamentaba en las fuentes orales que se recogieron a partir de entrevistas en profundidad semidirigidas, con un cuestionario base, un aspecto que ya presupone una relación desigual entre investigadora y área de estudio. Un hecho que se volvió a poner en evidencia en el momento de codificar las entrevistas transcritas -como hice- a través de los temas de interés de la propia Tesis Doctoral y que, en buena parte, tenía relación con el cuestionario base.

Podríamos decir que el interés no es la experiencia en sí de la persona entrevistada, sino el dar respuestas a los intereses de la investigación y de la investigadora, y esto ya presupone unas restricciones claras cuando desarrollamos investigaciones en geografía humana desde un compromiso crítico y de transformación social, además de un claro contrasentido por lo que respeta al feminismo, donde es o tendría que ser básico la combinación de análisis con acción social, teniendo un interés claro por la consecuención de resultados políticos. Este punto de partida ya presupone un final desolador, a mi entender, ya que condena a muchas investigaciones al estricto autoconsumo académico, y contribuye a esta carencia de fluidez e interacción mutua entre academia y mujeres y dinámicas propias de barrio.

¿Y cómo cambiar esta dinámica investigadora? En un primer momento, volviendo al proceso en el lugar más que insistir en la aplicación del método en el lugar. En ese sentido hay que entender que, ya durante el desarrollo del trabajo de campo, la rigidez metodológica se fuera flexibilizando, con la misma o mayor rigurosidad, generándose cambios y adaptaciones en las formas de plantear y desarrollar las entrevistas, los encuentros y contactos, así como la misma observación pasando a dinámicas más de participación directa y vinculación cotidiana con las áreas de estudio.

Se intentaba que todo lo que se iba presentando se fuera tratando en una escala de barrio, desarrollando temas previos y abriendo de nuevos. En todo caso... no era suficiente. Sobre todo por el hecho de la falta de arraigo al lugar y el transcurrir de los proyectos en los tiempos de estos lugares, que son muy diferentes a los que se imponen mudesde lo institucional $\mathrm{y}$, también, académico.

En por eso, y en un segundo lugar, que la experiencia investigadora me ha llevado ha intentar hacer de lo cotidiano y personal geografia, y tambien desde el ámbito académico. Es aquí donde se ha de situar mis primeras colaboraciones con un grupo de mujeres jóvenes de mi entorno cotidiano, participando del impulso de un colectivo que autodenominaron Kollectiu de Dones de Barberà (KDB) o colaborando con la organización de actividades. Se trataba de un grupo de mujeres no politizadas, al menos desde un punto de vista feminista, pero que el hecho de la necesidad de reunirse y generar un espacio (primero en lo íntimo para pasar a lo colectivo) para ellas las ha hecho politizarse y ser activas políticamente, tanto desde su propio colectivo como participando de otros espacios.

$\mathrm{Y}$ aquí también hay que situar el interés por impulsar un proceso investigador en un barrio, otra vez, de mi ciudad, La Romànica de Barberà del Vallès, donde el sujeto Mujer fuera central tanto en la temática del proyecto como en su mismo desarrollo, mirando de generar dinámicas de colaboración e interacción que tengan recorrido en el tiempo y con las mujeres que se entre en contacto, un proceso que en la actualidad se está desarrollando. Destacar, que en general, estamos hablando de un entornos social y urbano donde los niveles de implicación asociativa y política activa se habían mantenido en unos niveles bajos y débiles -tanto para hombres como para mujeres, pero aún más débiles en el caso de ellas- pero que en los últimos tiempos se muestran otras pautas asociativas y de participación donde la necesidad de encuentro, relación y autoorganización ha ayudado a emerger estos espacios y ha visibilizado a estas mujeres por ellas mismas.

\section{A modo de conclusión: la vinculación a ellas y al lugar}

El ejercicio de autoreflexión y revisitación entorno a una trayectoría investigadora vinculada al estudio de barrios humildes, centrando este ejercicio en la situación de las mujeres en estas àreas urbanas concretas, ha supuesto tanto una contribución más en el estudio de las mujeres en la sociedades contemporaneas como a la discusión de la práctica y desarrollo de la geografía. El hecho de describir, en general y otra vez más, una realidad social y espacial 
de discriminación para las mujeres, en este caso de mujeres que viven en barrios humildes en la región metropolitana de Barcelona, también a supuesto, y en particular, que se pongan de manifiesto vivencias y expresiones diversas de esta discriminación, aún compartiendo dinámicas y lugares que podríamos considerar más o menos homogéneas. Al mismo tiempo esta realidad también supone unas claras carencias o deficiencias, tanto desde el punto de vista de lo que podemos considerar la sociedad en general (se sigue reproduciendo la discriminación aunque existan políticas y discursos que quieran incidir en lo contrario) como desde el punto de vista del proceso investigador (se quiere contribuir, igual que las políticas y los discursos, a transformar esta realidad de discriminación) que muchas veces se queda en simple aplicación de métodos para un consumo estrictamente académico. En este contexto se ha situado el interés por ir más allá y no detenerse en la frustación, insistiendo en lo que podríamos llamar una geografía procesual, y dejando de lado una geografía sistemática, repetitiva de métodos $y$, en cierta manera, de errores en lo que acción social y política se refiere.

Una geografía procesual que, a mi modo de ver, de hacer y de sentir se tiene que centrar, sobre todo, en el hecho de vincularse al lugar y a sus tiempos, lo que en mi caso ha comportado un fortalecimiento de mi implicación asociativa y política en mi ciudad sin renunciar a la geografía ni al ejercicio académico y científico, dándole un sentido geográfico al activismo en mi entorno cotidiano. Es en este contexto de mi cotidianidad donde estoy situando en la actualidad mi forma de hacer geografía, con ellas y con el lugar, y también con sus tiempos, que ya son más nuestros tiempos o un tiempo compartido. Y hacer referencia a los tiempos es importante y necesario para entender el por qué de este ejercicio de autorreflexión, ya que en una trayectoria activista se hace necesario ir haciendo paradas periódicamente y continuamente, para pensar en lo hecho y qué hacer, y en compartirlo.

Vincularse a ellas, a sus espacios de relación, associación y acción política, y a sus tiempos, supone también desarrollar proyectos de intervención i/e investigación en los mismos barrios que tengan un compromiso claro con arraigar en el lugar, no desarrollar, como se ha hecho hasta ahora, proyectos temporales teledirigidos desde fuera donde lo conseguido en el barrio se desvanece a partir del mismo momento que se van los responsables externos del proyecto. Insistir en el proceso en sí y no en la aplicación en sí, como ya se ha comentado antes. Creo que desde lo institucional y lo no institucional se tiene que tener muy presente esta necesidad si se quiere ser social y políticamente útil. El arraigo al lugar tiene un potencial positivo en lo colectivo y comunitario, centrándonos en el ámbito de la vecindad, pero ¿porqué no centrarlo también en el ámbito de las investigadoras e investigadores y de las políticas públicas?

$\mathrm{Y}$, para terminar, reseñar y concretar algunas líneas de trabajo y de acción, desde lo institucional y no institucional, que se han puesto de manifiesto a lo largo del presente artículo, y que pueden ayudar a fortalecer el papel social y comunitario de las mujeres en los barrios y contribuir a la no reproducción de la discriminación por el hecho de ser mujer o ser considerada mujer: 1) aprovechar su vinculación y experiencia vivencial en sus áreas de residencia (aún cuando tiene un origen que tendríamos que considerar como discriminador y el objetivo tiene que ser superarlo) y el destacable nivel de participación asociativa (aún cuando no siempre desde posiciones que estamos acostumbradas a considerar como activas sino más bien pasivas en lo que consideramos como político) para analizar, reflexionar y actuar con ellas; 2) aprovechar el uso híbrido de espacios relacionales que ejercen en su cotidianidad (tradicionalmente vistos de forma separada entre públicos o privados) para introducir pautas diferentes de socialización en lo doméstico y familiar, ejerciendo un contrapunto a la reproducción de la discriminación que se produce en este ámbito.

Añadiría una tercera línea de trabajo y acción y sería la que se centraría en el caso del sujeto Hombre, tanto para reconocer la importancia del papel de aquellas personas que se identifican como hombres y que se posicionan y actúan activamente por la erradicación de la discriminación por cuestiones de identidad sexual y de género, como, por otro lado, para reconocer la necesidad de intervenir activamente sobre el sujeto Hombre, que tiene un papel decisivo en imponer mecanismos de reproducción de la discriminación y el control social. En este sentido, creo que es importante pasar de las políticas de género o de mujeres enfocadas a colectivos concretos, para incidir desde lo político e institucional y no institucional, por un lado, en la fortalecimiento y consolidación de dinámicas de resistencia (que expresan tanto identidades 'mujer' como de 'hombre') $\mathrm{y}$, por otro lado, en el debilitamiento y erradicación de las dinámicas de dominio (que expresan, también, unas y otras identidades). Son aspectos muy generales los que estoy comentando, y que necesitan de una mayor concreción y definición, y que actualmente miro de desarrollar y aplicar en mi forma de hacer geografía, aunque de una forma incipiente. En todo caso creo que es importante compartirlos, ya que el interés es no hacer las cosas individualmente sino 
colectivamente, aportando cada una su grano de arena.

* Este artículo también ha sido posible gracias a políticas públicas de ayuda a la investigación básica del Ministerio de Educación (Gobierno español, ref. BSO2000-0497, BSO2003-01348, SEJ2006-09837) a través de proyectos impulsados por el Grup de Recerca de Geografia i Gènere en los últimos años.

1 En este tercer proceso tengo que mencionar también la inclusión de un proyecto de investigación con ayuda pública, a través del Institut Català de les Dones (Generalitat de Catalunya, ref. ASC/1148/2010), donde han participado activamente Maria Dolors Garcia Ramon (Universitat Autònoma de Barcelona), Rosa Cerarols Ramírez (Universitat Pompeu Fabra) y Antoni Luna Garcia (Universitat Pompeu Fabra), integrantes también del Grup de Recerca i Gènere.

2 Algunas citas, como la referenciada, han sido traducidas a lengua castellana, ya que fueron entrevistas que se realizaron en lengua catalana, idioma propio y oficial en Catalunya.

3 Los "Plans de Barri" ("Planes de Barrio") son programas de actuación sociocomunitaria y urbanística, con una importante inversión económica pública, impulsada desde el gobierno autonómico catalán, con la participación de los ayuntamientos, destinados a fortalecer la cohesión social en barrios que han padecido una sistemática precarización, tanto desde el punto de vista material como social.

\section{Referências}

ARANGO, Joaquín (2007). Les primeres migracions del segle XX a Catalunya. En: CENTRE D'ESTUDIS DEMOGRÀFICS (coord.). Immigració. Les onades migratòries en la Catalunya contemporània. Barcelona: Fundació Lluís Carulla, p. 19-34, 2007.

ARRIF, Abdelmajid. Variations spatiales du privé et du public à travers les exemples de Ben M'Sik et Hay Moulay Rachid à Casablanca. Les Cahiers d'URBAMA, n. 13, p. 61-89, 1997.

BALLARÍN, César; CASAS, Just; MÁRQUEZ, Manel. Ca n'Anglada. Lluita d'un barri. Història social de Ca n'Anglada: el moviment veïnal 1950-1995. Terrassa: Associa-ció de Veïns de Ca n'Anglada, 1997.
BATALLA, Vicenç. Ca n'Anglada, síntesi de les barriades obreres. En: Al Vent, n. 87. p. 13-17, 1986.

BENSON, Koni; NAGAR, Richa. Collaboration as Resistance? Reconsidering the processes, products, and possibilities of feminist oral history and ethnography. En: Gender, Place and Culture, v. 13, n. 5, p. 581-592, 2006.

BLUNT, Alison. Cultural geography: cultural geographies of home. En: Progress in Human Geography, v. 29, n. 4, p. 505-515, 2005.

BONDI, Liz; DOMOSH, Mona. On the contours of public space: a tale of three women. En: Antipode, v. 30, n. 3, p. 270-289, 1998.

CAHILL, Caitlin. The personal is political: developing new subjectivities through participatory action research. En: Gender, Place and Culture, v. 14, n. 3, p. 267-292, 2007.

CANDEL, Francesc. Els altres catalans. Barcelona: Edicions 62, 1964.

CHATTERTON, Paul; PICKERILL, Jenny. Everyday activism and transitions towards post-capitalist worlds. En: Transactions of the Institute of British Geographers, v. 35, n. 4, p. 475-490, 2010.

CASTELLS, Manuel. Ciudad, democracia y socialismo. Madrid: Siglo Veintiuno Edi-tores, 1977.

CHRISTIE, María Elisa. Kitchen space: gendered territory in Central Mexico. Gender, Place and Culture, v. 15, n. 6, p. 653-661, 2006.

CRANG, Mike. Qualitative methods: the new ortodoxy? Progress in Human Geography, v. 26, n. 5, p. 647-655, 2002.

CRANG, Mike. Qualitative methods: there is nothing outside the text?. Progress in Human Geography, v. 29, n. 2, p. 225-233, 2005.

DAVIES, Gail; DWYER, Claire. Qualitatives methods: are you enchanted or are you alienated?. En: Progress and Human Geography, v. 31, n. 2, p. 257266, 2007.

DAY, Kirsten. Constructing masculinity and women's fear in public space in Irvine, California. En: Gender, Place and Culture, v. 8, n. 2, p. 109-127, 2001. 
DÍAZ-CORTÉS, Fabià. Espai públic, arrelament al lloc i vida quotidiana: el cas del barri de $\mathrm{Ca}$ n'Anglada de Terrassa. Tesina (Doctorado en Geografía Humana), Departa-ment de Geografia, Universitat Autònoma de Barcelona, Barcelona (no publicada), 2004.

DÍAZ-CORTÉS, Fabià. Espai públic, vida quotidiana $i$ identitat de barri a Terrassa: la construcción material i social de Can Palet i Ca n'Anglada a través d'una geografia de la proximitat. Tesis (Doctorado en Geografía Humana) Department de Geografia, Universitat Autònoma de Barcelona, Barcelona. Disponível em < http://www.tesisenxarxa.net/...., 2009.

DRIVER, Felix. On geography as a visual discipline. En: Antipode, v. 35, n. 2, p.227-231, 2003.

EKINSMYTH, Carol. Feminist methodology. In: P. SHURMER-SMITH (ed.). Doing Cultural Geography. London: Sage Publications, p. 177-185, 2002.

ENGLAND, Kim. Getting personal: reflexivity, positionality and feminist research. Professional Geographer, v. 46, n. 1, p. 80-89, 1994.

GARCIA-RAMON, Maria Dolors. Espacios asexuados o masculinadades y feminida-des espaciales?: Hacia una geografía del género. En: Semata, Ciencias Sociais e Humanidades, n. 20, p. 25-51, 2008.

GEORGE, Karen; STRATFORD, Elaine. Oral history and Human Geography. En: I. HAY (ed.). Qualitative Research Methods in Human Geography. Oxford: Oxford University Press, p. 139-151, 2010.

GLESON, Brendan J. A public space for women: the case of charity in colonial Mel-bourne. En: Area, v. 27, n. 3, p. 193-207, 1995.

HAY, Iain. Qualitative Research Methods in Human Geography. Oxford: Oxford University Press, 2010.

HAYDEN, Dolores. The power of place. Urban landscapes as public history. Cam-bridge: MIT Press, 1995.

HYANS, Melissa. Adolescent Latin bodyspaces: making homegirls, homebodies and homeplaces. En: Antipode, v. 35, n. 3, p. 536-558, 2003.
KATZ, Cindy. Playing in the field. En: Professional Geographer, v. 46, n. 1, p. 67-72, 1994.

KEARNS, Robin A. Seeing with Clarity: Undertaking Observational Research. En: I. Hay (ed.). Qualitative Research Methods in Human Geography. Oxford: Oxford University Press, p. 241-258, 2010.

KERN, Leslie. In Place and At Home in the City: Connecting privilege, safety and be-longing of women in Toronto. En: Gender, Place and Culture, v. 12, n. 3, p. 357-377, 2005.

KOSKELA, Hille. Bold walk and breakings: women's spatial confidence versus fear of violence. En: Gender, Place and Culture, v. 4, n. 3, p. 301-319, 1997.

KOSKELA, Hille. Gendered exclusions: women's fear of violence and changing rela-tions to space. En: Geografiska Annaler, v. 81B, n. 2, p. 111-124, 1999.

LEE, Jo-Anne. Gender, ethnicity, and hybrid forms of community-based urban acti-vism in Vancouver, 19571978: The Strathcona story revisited. En: Gender, Place and Culture, v. 14, n. 4, p. 381-407, 2007.

LLIGADES, Josep; DE MAYA, Juan Francisco. Cerdanyola, el barri gran de Mata-ró. 1920-2000. Mataró: Patronat Municipal de Cultura (Caps de Bou, 24), 2000.

LOBO, Michelle. Negotiating emotions, rethinking otherness in suburban Melbourne. En: Gender, Place and Culture, v. 17, n. 1, p. 99-114, 2010.

LONGHURST, Robin. "Plots, plants and paradoxes: contemporary domestic gardens in Aotearoa/New Zealand". En: Social \& Cultural Geography, v. 7, n. 4, p. 581-593, 2006.

MADGE, Claire. Public parks and the geography of fear. En: Tijdschrift voor eco-nomische en sociale geografie, v. 88, n. 3, p. 237-250, 1997.

MARÍN, Martí. D’immigrants a ciutadans. Barcelona: Ajuntament de Sant Adrià de Besòs i Museu d'Història de la Immigració de Catalunya, 2004.

MCDOWELL, Linda. Multiple voices-speaking from inside and outside the project. En: Antipode, v. 24, p. 56-72, 1992. 
MERRIL, Heather. Space agents: anti-racist feminism and the politics of scale in Turin, Italy. En: Gender, Place and Culture, v. 11, n. 2, p. 189-204, 2004.

MILLS, Ami. Gender and Mahalle (Neigborhoood) space in Istanbul. En: Gender, Place and Culture, v. 14, n. 3, p. 335-354, 2007.

MONQID, Safaa. Les femmes marocaines entre privé et public. En: Villes en Pa-rallele, n. 32-34, p. 398405, 2001.

NAVEZ-BOUCHNINE, Françoise. De l'espace public occidental aux espaces publics non occidentaux. En: Villes en Parallele, 32-34, p. 120-134, 2001.

NELLO, Oriol (dir.). Llei de barris, la: Una aposta collectiva per la cohesió social. Barcelona: Generalitat de Catalunya. Departament de Política Territorial i Obres Públi-ques, 2009.

PAIN, Rachel; TOWNSHEND, Tim. A safer city centre for all? Senses of 'community safety' in Newcastle upon Tyne. En: Geoforum, v. 33, n. 1, p. 105-119, 2002.

PALMARY, Ingrid. 'In your experience': research as gendered cultural translation. En: Gender, Place and Culture, v. 18, n. 1, p. 99-113, 2011.

PUJADAS, Isabel. Les migracions dels anys seixanta a Catalunya. En: CENTRE D'ESTUDIS DEMOGRÀFICS (coord.). Immigració. Les onades migratòries en la Catalunya contemporània. Barcelona: Fundació Lluís Carulla, p. 35-48, 2007.

REID, Bryonie. Rearranging the ground': public and private space in Belfast, North-ern Ireland. En: Gender, Place and Culture, v. 15, n. 5, p. 489-503, 2008.

RILEY, Mark; HARVEY, David. Talking geography: on oral history and the practice of geography. En: Social \& Cultural Geography,v. 8, n. 3, p. 345-351, 2007.

RODRÍGUEZ, Estela; ARAYA, Mariel. Buscando habitar la ciudad. El reto de la vivi-enda para las mujeres inmigradas en Madrid y Barcelona. En: Scripta Nova. Revista Electrónica de Geografía y Ciencias Sociales. Disponível em: $<$ http://www.ub.edu/geocrit/sn/sn-146(062).htm> 2003.
RUDDICK, Susan. Constructing Difference in Public Spaces: Race, Class and Gender as Interlocking Systems. En: Urban Geography, v. 17, n. 2, p. 132151, 1996.

TAYLOR, Steven J; BOGDAN, Robert. Introduction to qualitative research method. New York: Wiley, 1996.

URÍA, Paloma. El feminismo que no llegó al poder. Trayectoría de un feminismo crítico. Madrid: Talasa Ediciones, 2009.

VAIOU, Dina. Migration and Socio-Spatial Transformations in Southern European Ci-ties. En A. PIKE; A. RODRÍGUEZ-POSE y J. TOMANEY (eds.). Handbook of local and Regional Development. London: Routledge, p. 470-481, 2010.

VALENTINE, Gill. Social Geographies. Space and Society. London: Pearson, 2001.

VALENTINE, Gill. Living with difference: reflections on geographies of encounter. En: Progress in Human Geography, v. 32, n. 3, p. 321-335, 2008.

VÁZQUEZ MONTALBÁN, Manuel; MORENO, Eduard. Barcelona, cap on vas? Diàlegs per a una altra Barcelona. Barcelona: Llibres de l'Índex, 1991.

YEOH, Brenda; HUANG, Shirlena. "Negotiating public space: strategies and styles of migrant female domestic workers in Singapore". En: Urban Studies, v. 35, n. 3, p. 583-602, 1998.
Recebido em: 25 de novembro de 2011. Aceito em: 22 de fevereiro de 2012. 